J. Dairy Sci. 99:2435-2436

http://dx.doi.org/10.3168/jds.2015-10712

(C) American Dairy Science Association ${ }^{\circledR}, 2016$.

\title{
Letter to the Editor: Comments on Journal of Dairy Science statistical unit policy as it relates to pen-based animal studies
}

Peter H. Robinson

Department of Animal Science, University of California, Davis 95616
I write about the Journal of Dairy Science policy of not accepting experiments that use random(cow) nested within replicated pens as the statistical unit because they appear to not meet the criterion of being from a study where "The experimental unit is the smallest unit to which an individual treatment is imposed" (J. Dairy Sci. 98: Instructions, 1-17; http://www.journalofdairyscience.org/content/inst-auth), in contrast to accepting the alternative biological and statistical view that "The experimental unit is the smallest unit in which an individual treatment can be measured."

In this regard, it might be interesting to examine the statistical analysis of one representative data set $(3 \times 3$ Latin square study with 125 cows in each of 3 pens on a commercial dairy) using statistical models of random(cow) nested within pen as the experimental unit (Model 1) versus pen means as the statistical unit (Model 2). Some key response parameters are in Table 1.

Model 1 uses random(cow) nested within pen in the statistical model, and so it "sees" all cow data and considers cow 5444 (for example) in period 1 as the same cow in periods 2 and 3 . Model 2 drops individual cow data in favor of pen means (per Journal of Dairy Science policy). Thus, 1,125 lines of data (375 cows in 3 periods) for Model 1 reduce to 9 lines of data in Model 2 (pen means as averages of all cows in each of 9 pen-period combinations). Except for arithmetic rounding, means are the same between models, but using Model 1 compared with Model 2 results in important changes in standard errors of the means (SEM) and $P$-values. For example, SEM are always lower with Model 2 and, of 12 treatment $P$-values, 7 are lower with Model 2 than with Model 1. This contrasts to the view of some animal scientists, who express skepticism of Model 1 because they judge it as statistical trickery to depress $P$-values so that treatment differences that do not exist are declared. Clearly this is not so. It is also evident that $P$-value changes between Models 1 and 2 are not random, because 5 of 6 values for the treatment comparisons of milk yield and milk protein percentage (parameters with relatively low variation

Table 1. Statistical model comparisons

\begin{tabular}{|c|c|c|c|c|c|c|c|}
\hline \multirow[b]{2}{*}{ Parameter and model ${ }^{1}$} & \multicolumn{3}{|c|}{ Treatment } & \multirow[b]{2}{*}{ SEM } & \multicolumn{3}{|c|}{$P$-value } \\
\hline & 1 & 2 & 3 & & 1 vs. 2 & 1 vs. 3 & 2 vs. 3 \\
\hline \multicolumn{8}{|l|}{ Milk (kg/d) } \\
\hline Model 1 & 47.78 & 47.91 & 48.91 & 0.413 & 0.75 & 0.01 & 0.03 \\
\hline Model 2 & 47.76 & 47.94 & 48.93 & 0.314 & 0.73 & 0.12 & 0.15 \\
\hline \multicolumn{8}{|l|}{ Milk fat (\%) } \\
\hline Model 1 & 3.28 & 3.26 & 3.28 & 0.028 & 0.53 & 0.84 & 0.67 \\
\hline Model 2 & 3.28 & 3.26 & 3.28 & 0.012 & 0.35 & 0.73 & 0.51 \\
\hline \multicolumn{8}{|l|}{ Milk protein (\%) } \\
\hline Model 1 & 2.85 & 2.86 & 2.85 & 0.011 & 0.29 & 0.75 & 0.17 \\
\hline Model 2 & 2.85 & 2.86 & 2.85 & 0.006 & 0.35 & 0.99 & 0.35 \\
\hline \multicolumn{8}{|l|}{$\mathrm{SCC}\left(\times 10^{3}\right.$ cells $\left./ \mathrm{mL}\right)$} \\
\hline Model 1 & 65.2 & 68.8 & 79.1 & 9.18 & 0.71 & 0.16 & 0.30 \\
\hline Model 2 & 65.3 & 68.7 & 79.1 & 2.16 & 0.38 & 0.045 & 0.08 \\
\hline
\end{tabular}

${ }^{1}$ Model $1=$ cow in model [as random cow(pen)]; Model 2 = pen means (pen fixed); Journal of Dairy Science policy.

Received December 3, 2015

Accepted January 6, 2016.

${ }^{1}$ Corresponding author: phrobinson@ucdavis.edu 
in responses of individual cows among treatments) increase if Model 1 is replaced by Model 2. In contrast, for milk fat percentage and SCC (which have relatively high variation within cows among treatments), all 6 $P$-values for treatment comparisons decrease if Model 1 is replaced by Model 2. This demonstrates the biological and statistical problem of destroying cow-based variance profiles by averaging cows within pens before statistical analysis, in that biological variation within cows in treatment responses are removed, leading to an artificially low (biologically speaking) SEM (Table 1). Such an approach increases the likelihood that false treatment differences will be declared in parameters with high variation within cows among treatments and that true treatment differences in parameters with low variation within cows among treatments will not be detected. Of course, SEM do not always get smaller with a pen means model, but ignoring a known random effect always gives an incorrect SEM.

I am not advocating publication of studies with unreplicated pens. Replication by using more than one pen per treatment, or by crossing pens over, is important to prevent confounding treatment with pen. My argument relates to the appropriate statistical unit in studies with replicated pens.

I hope that the Journal of Dairy Science will revisit their policy relative to statistical analysis of groups of animals within replicated pens to assess whether use of pen means is biologically inappropriate, and whether appropriate statistical models should preserve individual cow variance profiles by nesting random(cow) within replicated pens whenever possible. 